\title{
Cerebral infarction due to carotid occlusion and carbon monoxide exposure II. Influence of preganglionic cervical sympathectomy
}

\author{
JÖRG IGLOFFSTEIN, RUDOLF LAAS \\ From the Department of Neuropathology, Eppendorf Hospitals, University of Hamburg, Himburg, Federal \\ Republic of Germany
}

SUMMARY Unilateral cerebral infarcts were produced in the rat by ligation of one common carotid artery and subsequent exposure to carbon monoxide. The incidence and extension of brain infarcts was increased in animals with additional ipsilateral cervical preganglionic sympathectomy. Sympathectomy did not affect markedly the respiration and systemic circulation. The effect of sympathectomy was attributed to a cutaneous vasodilation, leading to an extracranial steal phenomenon.

The role of the cervical sympathetic innervation of the cerebral vessels is controversal. It is generally accepted that the influence of the sympathetic innervation on the extracranial vasculature is much more effective than on the intracranial bed. Since the extra- and intracranial vascular beds are connected in parallel, and since flow through the carotid bifurcation is not hampered by ligation of the common carotid artery, our model permits the study of the effects of ipsilateral cervical sympathectomy on the cephalic vasculature.

\section{Materials and methods}

The experiments were performed with male rats (Chbb:THOM strain).

\section{Series $I$}

In 60 of 133 animals (300-400 $\mathrm{g}$ body weight) the fibres of the cervical sympathetic trunk were divided at the time of the common carotid artery dissection. In the remaining 73 animals the sympathetic chain was allowed to remain intact. The cerebral lesions were studied histologically in the first 29 experimental and 49 control animals. Occurrence of enophthalmos and ptosis were taken as indicators of adequate sympathetic interruption.

Series II

In a separate series of 16 animals the ipsilateral external

Address for reprint requests: Rudolf Laas, MD, Department of Neuropathology, Eppendorf Hospitals, University of Hamburg, Martinistrasse 52, D-2000 Hamburg 20, Fed Rep Germany.

Received 6 April 1982 and in revised form 18 January 1983. Accepted 4 March 1983. carotid artery also was ligated at the time of common carotid artery ligation. Sixteen animals with open external carotid artery served as controls.

\section{Series III}

In animals with enophthalmos and ptosis the presence of miosis, the most important sign of sympathetic deficit, was demonstrated as follows: in four animals without dissection of the common carotid artery a preganglionic cervical sympathectomy was performed. After 9 to 50 days the animals were sedated (haloperidol $0.2 \mathrm{mg} / \mathrm{kg}$ body weight) and 30 minutes later both eyes were photographed after $60 \mathrm{~s}$ of complete darkness. We used an operating microscope and a light flash for photographic purposes. A series of six photographs was taken and the entire sequence was repeated twice. The greatest diameter of the pupil was measured on the prints.

\section{Series IV}

In 18 unanaesthetised and unrestrained animals the following parameters were monitored before, during and for 80 minutes after carbon monoxide exposure $(3000 \mathrm{ppm}$ in room air, 70 minutes duration): systemic arterial blood pressure, heart rate, respiration rate, and EEG. For the recordings a slip ring assembly was used (for details cf ref 1). In seven of these animals the ipsilateral sympathetic chain had been divided.

\section{Results}

\section{Series I}

Lethality. After carbon monoxide exposure 27 of 60 animals with Horner's syndrome and six of 73 animals without Horner's syndrome died $(\mathrm{p}<0.001)$. The dead animals had massive ipsilateral brain oedema. During carbon monoxide exposure three 

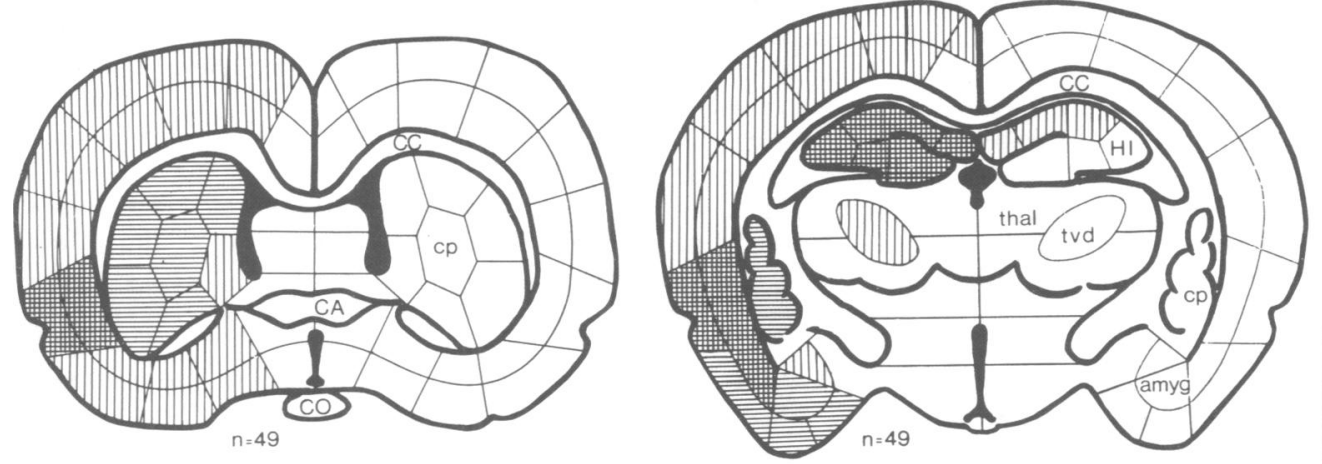

Incidence of

lesions $(\%)$
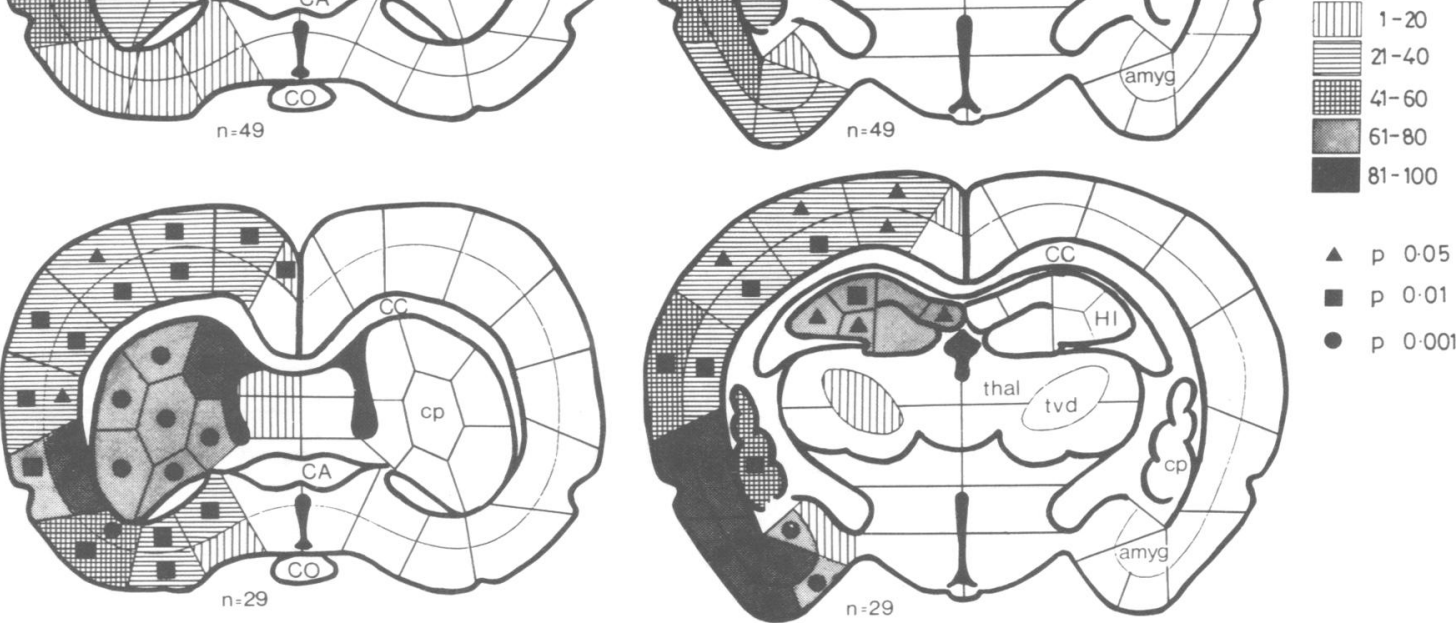

Fig 1 Pattern of infarct distribution in control rats, above $(n=49)$ and in sympathectomised rats $(n=29)$, below.
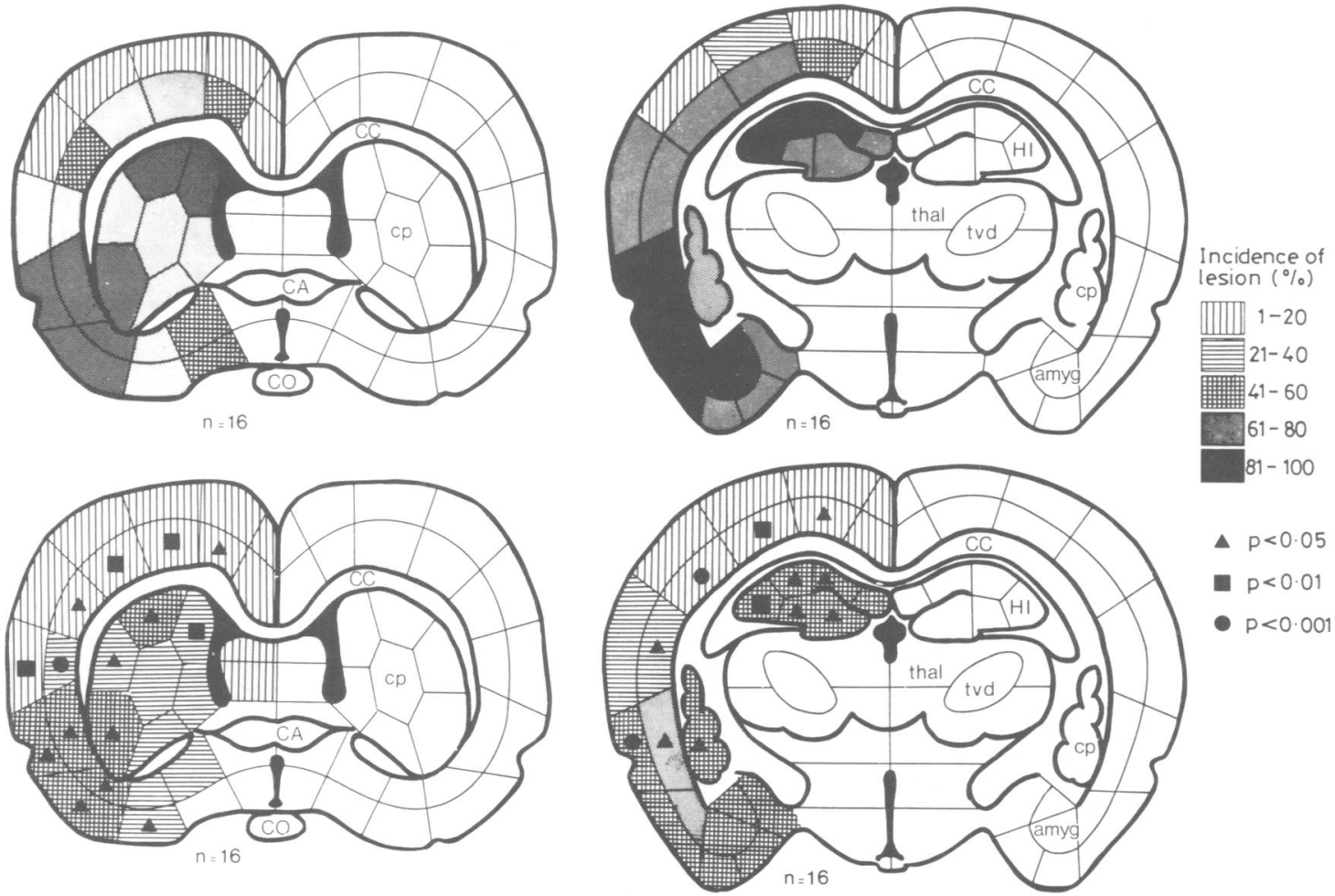

Fig 2 Pattern of infarct distribution in sympathectomised animals without (above) and with (below) additional ligation of the ipsilateral external carotid artery For abbreviations see ref 1, fig 4. 
animals died both in the experimental and in the control group.

Histological findings. As shown in fig 1 there was no difference in the pattern of lesions between experimental and control group, but there were highly significant differences in the frequency and extent of infarctions in favour of the control group.

\section{Series II}

In this separate series two experimental and two control animals died after carbon monoxide exposure. The regional infarct frequency was reduced in the experimental group (fig 2). In the experimental group with additional ligation of the ipsilateral external carotid artery the infarcts were significantly more extensive.

\section{Series III}

In all animals with enophthalmos and ptosis the mean pupil diameter was smaller on the affected side $(0.001>p<0.05)$

\section{Series IV}

Figure 3 summarises the course of the parameters recorded in the 18 unrestrained rats. Up to the 50th minute no difference in the circulatory parameters between control and experimental animals

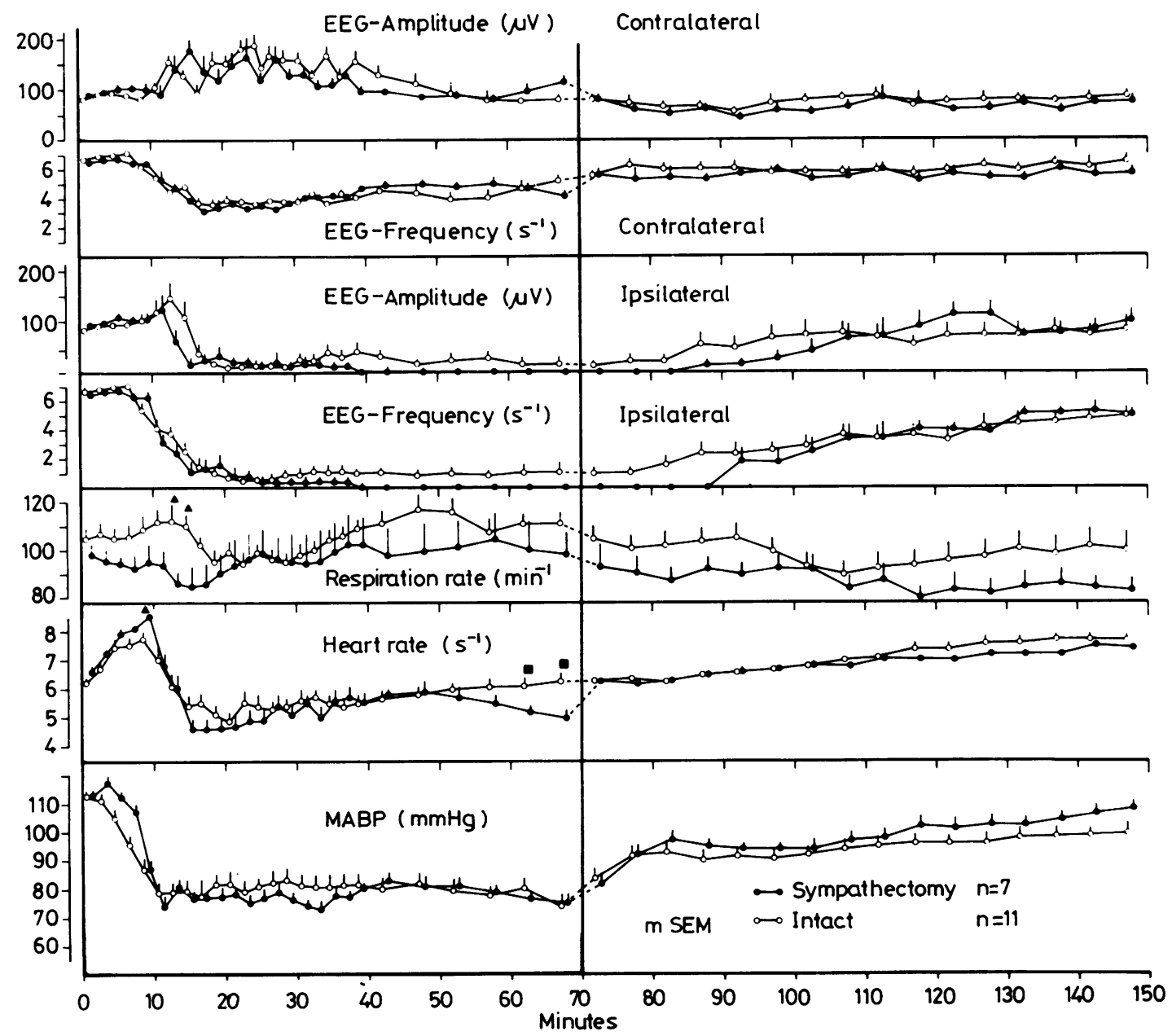

Fig 3 Time course of mean arterial blood pressure (MABP), heart rate, respiratory rate, and of the predominant EEG frequency and amplitude in 7 sympathectomised rats and in 11 control animals during and after an exposure to carbon monoxide. 
appeared. After the 50th minute a nearly linear decrease of heart rate was observed in the sympathectomised rats, falling to $1 \mathrm{beat} / \mathrm{s}$ at the end of carbon monoxide exposure. Immediately after cessation of carbon monoxide exposure heart rate quickly rose again to the level of the control group. Blood pressure, respiratory rate, EEG amplitudes and frequencies did not differ in the two groups during the exposure or in the recovery period.

\section{Discussion}

Our own pathophysiological findings ${ }^{1}$ showed that carbon monoxide-induced hypoxia resulted in hypotension of 70 to $80 \mathrm{~mm} \mathrm{Hg}$ which was the main factor responsible for the development of regional cerebral infarcts. We attribute the greater extent of brain infarcts in sympathectomised animals to an additional fall of the arterial blood pressure distal to the ligation of the common carotid artery. This fall is caused by the marked dilating effect of sympathectomy on the cutaneous vasculature. The resistance of skin arteries to blood flow is maintained in a tonic manner by sympathetic innervation ${ }^{2-5}$ in contrast to muscle and brain where the vascular resistance is mainly intrinsically regulated. ${ }^{6-8}$ Regulation of arterial and venous cutaneous vessels is exerted via sympathetic efferents mainly by alpha-receptors. ${ }^{9}$ Skin vasodilation in animals lacking sweat glands is brought about by reduction of adrenergic constrictor tone. ${ }^{2}$ Our own histological preparations (unpublished data) have shown that rat skin is devoid of sweat glands.

As shown by direct observation of the flow direction in rats, ${ }^{1}$ the extracranial cephalic circulation acts like a sink for the intracranial blood flow after common carotid artery ligation. Consequently, sympathectomy enhances this leakage and lowers the arterial blood pressure in the distal common carotid artery. Pressure recordings in the rabbit's ciliary artery after sympathectomy and sympathetic stimulation, ${ }^{1011}$ and in the dog's carotidal sinus after sympathetic stimulation, ${ }^{12}$ support this conception.

Since the cutaneous vasculature is mainly supplied by the external carotid artery, we tried to neutralise the effect of sympathectomy by ligating the ipsilateral external carotid artery. There was then a reduction of the extent of infarction. This finding is in keeping with observations of others in dogs, ${ }^{13} \mathrm{rab}$ bits $^{1415}$ and monkeys. ${ }^{16}$

There is good evidence that in states of functional anaemia and hypotension a baroreceptor-induced increase of the constrictor tone takes place counteracting the local hypoxic vasodilation. ${ }^{17}$ Unilateral preganglionic sympathectomy may have exerted an influence not only by eliminating basal vasoconstric- tor tone, but also by blocking additional baroreceptor-mediated sympathetic tone of skin vessels during exposure to carbon monoxide.

The function of the sinus baroreceptors may have been altered by the sympathectomy. The cerebrovascular response to hypoxia is known to be independent of sinus baroreceptor function. ${ }^{18}$ Contrary to the effects of sympathetic stimulation, ${ }^{19-22}$ sympathectomy increases systemic blood pressure and the sinus response to the lowering of pressure within the sinus. ${ }^{23}{ }^{24}$ Both responses would improve perfusion by raising blood pressure rather than lowering it.

From recordings in the unanaesthetised and unrestrained rats we know that neither systemic blood pressure nor heart rate is influenced by distal preganglionic sympathectomy, leaving intact the efferent sympathetic cardiac innervation, which originates from the inferior and medial cervical ganglia. ${ }^{25}$ Direct effects of pCO on medullary centres may be responsible for the bradycardia occurring without further decrease of systemic blood pressure in the sympathectomised rats from the 50th minute of exposure onwards and disappearing immediately thereafter.

Sympathectomy may have exerted effects not only on the extracranial vasculature, but also on the cerebral vessels themselves, since there is an adrenergic innervation of the pial arteries ${ }^{26-32}$ and also of the intracerebral arteries. ${ }^{33}$ The postganglionic perikarya are located in the superior cervical ganglia. ${ }^{2630} \mathrm{~A}$ constrictor effect of sympathetic stimulation has been demonstrated in several investigations (for example ref 34), in others it was missed or negligible compared with the effect on the extracerebral cephalic vessels. ${ }^{53}{ }^{36}$ A neurogenically mediated constrictor tone, leading to vasodilation after sympathectomy, has not been identified. . $^{37-40}$ Possibly the sympathetic effect on brain vessels is modifred by pathophysiological conditions. Participation in autoregulation, especially in prevention of superperfusion, and in protection of the bloodbrain-barrier have been discussed..$^{41-48}$ Hypocapnia tends to mitigate sympathetic effects; ${ }^{43}$ slight hypocapnia developed during carbon monoxide exposure in our experiments. ${ }^{1}$ All these presumed protective effects cannot explain our findings.

Thus, the dilating effect of the sympathectomy on the skin vessels appeared to predominate in our experiments, representing an extracranial steal from the cerebral circulation.

The authors are indebted to Mrs A Jakob for skilful technical assistance. 


\section{References}

${ }^{1}$ Laas R, Igloffstein J, Meyerhoff S. Cerebral infarction due to carotid occlusion and carbon monoxide exposure. I. Pathophysiological and neuropathological investigations. J Neurol Neurosurg. Psychiatry 1983;46:756-67.

${ }^{2}$ Celander O, Folkow B. A comparison of the sympathetic vasomotor fibre control of the vessels within the skin and the muscles. Acta Physiol Scand 1953;29:241-50.

${ }^{3}$ Folkow B. Nervous control of the blood vessels. Physiol Rev 1955;35:629-63.

${ }^{4}$ Green HD, Kepchar JH. Control of peripheral resistance in major systemic vascular beds. Physiol Rev 1959;39:617-86.

${ }^{5}$ Meyer MW, Smith KA, Klassen AC. Sympathetic regulation of cephalic blood flow. Stroke 1977; 8:197-201.

${ }^{6}$ Folkow B. Autoregulation in muscle and skin. Circulat Res 1964;Suppl. I 14/15:1-19.

7 Jones RD, Berne RM. Intrinsic regulation of skeletal muscle blood flow. Circulat Res 1964;14:126-38.

${ }^{8}$ Rosenblum WI. Neurogenic control of cerebral circulation. Stroke 1971;2:429-39.

${ }^{9}$ Green HD, Howard WB, Kenan LF. Autonomic control of blood flow in hind paw of the dog. Am J Physiol 1956;187:469-72.

${ }^{10}$ Bill A. Effects of cervical sympathetic tone on blood pressure and uveal blood flow after carotid occlusion. Exp Eye Res 1963;2:203-9.

"Best M, Masket S, Rabinovitz AZ. Effect of sympathetic stimulation on ocular hemodynamics. Invest Ophthalmol 1972;11:211-20.

12 Iriuchijima J. Properties of arterial collateral vessels. In: Betz E, ed. Vascular Smooth Muscle. Heidelberg: Springer, 1972:110-11.

${ }^{13}$ Nusselt H. Beitrag zur Unterbindung der Arteria carotis communis. Chirurg 1946/47;17/18:503-5.

${ }^{14}$ Chungcharoen D, Daly M deB, Neil E, Schweitzer A. The effect of carotid occlusion upon the intrasinual pressure with special reference to vascular communications between the carotid and vertebral circulation in the dog, cat and rabbit. J Physiol (Lond) 1952;117:56-76.

${ }^{15}$ Musella R. Effects of bilateral external carotid artery ligation on cerebral circulation in the rabbit. Arch Sci Biol (Bologna) 1965;49:1-53.

${ }^{16}$ Abraham J, Shetty G, Chandy J. Preliminary observation on the hemodynamics of the internal carotid artery following bilateral external carotid ligation in the monkey. $J$ Neurosurg $1971 ; 35: 192-6$.

${ }^{17}$ Chalmers JP, Korner PI. Effects of arterial hypoxia on the cutaneous circulation of the rabbit. $J$ Physiol (London) 1966;184:685-97.

18 Traystman RJ, Fitzgerald RS. Cerebrovascular response to hypoxia in baroreceptor- and chemoreceptordenervated dogs. Am J Physiol 1981;241:H724 H731.

${ }^{19}$ Kezdi P. Control by the superior cervical ganglion of the state of contraction and pulsatile expansion of the carotid sinus arterial wall. Circulat Res 1954;2:36771.

${ }^{20}$ Bagshaw RJ, Peterson LH. Sympathetic control of the mechanical properties of the canine carotid sinus. Amer J Physiol 1972;222:1462-8.

${ }^{21}$ Kalkoff W. Die Reflexbeeinflussung des Blutdruckes während Adrenalineinwirkung am KarotissinusÄußerung einer spezifischen, von der Pressorezeption unterscheidbaren Funktion. Verh Dtsch Ges Kreisl aufforsch 1959;25:173-8.

${ }^{22}$ Sampson SR, Mills E. Effects of sympathetic stimulation on discharges of carotid sinus baroreceptors. Am J Physiol 1970;218:1650-3.

${ }^{23}$ Hegedus StA, Cahill MB, Grausky LR, Shackelford RT, Point P. Cervical sympathectomy and cerebrospinal fluid pressure. Arch Surg 1965;90:418-21.

${ }^{24}$ Krieger EM. Carotid occlusion in the rat: circulatory and respiratory effects. Acta Physiol Lat-Amer 1963; 13:350-7.

${ }^{25}$ Brown AM. Cardiac sympathetic adrenergic pathways in which synaptic transmission is blocked by atropine sulphate. J Physiol (London) 1967;191:271-88.

${ }^{26}$ Falck B, Mchedlishvili GI, Owman CH. Histochemical demonstration of adrenergic nerves in cortex-pia of rabbit. Acta Pharmacol Toxicol (Copenh) 1965;23:133-42.

${ }^{27}$ Fraser RAR, Stein BM, Barrett RE, Pool JL. Noradrenergic mediation of experimental cerebrovascular spasm. Stroke 1970;1:356-62.

${ }^{28}$ Iwayama $T$. Ultrastructural changes in the nerves innervating the cerebral artery sympathectomy. Z Zellforsch 1970;109:465-80.

${ }^{29}$ Purdy RE, Bevan JA. Adrenergic innervation of large cerebral blood vessels of the rabbit studied by fluorescence microscopy. Stroke 1977;8:82-7.

${ }^{30}$ Iwayama T, Furness JB, Burnstock G. Dual adrenergic and cholinergic innervation of the cerebral arteries of the rat. Circulat Res 1970;26:635-46.

${ }^{31}$ Nelson E, Rennels $M$. Innervation of intracranial arteries. Brain 1970;93:475-90.

${ }^{32}$ Nielsen KC, Owman $\mathrm{CH}$, Sporrong B. Ultrastructure of the autonomic innervation apparatus in the main pial arteries of rats and cats. Brain Res 1971;27:25-32.

${ }^{33}$ Cervós-Navarro J, Matakas F. Electron microscopic evidence for innervation of intracerebral arterioles in the cat. Neurology (Minneap) 1974;24:282-6.

${ }^{34}$ Auer LM, Johansson BB, Lund S. Reaction of pial arteries and veins to sympathetic stimulation in the cat. Stroke 1981;12:528-31.

${ }^{35}$ Barber BJ, Martin JS, Rapela CE. Analysis of the effect of bilateral sympathetic stimulation on cerebral and cephalic blood flow in the dog. Stroke 1978;8:29-34.

${ }^{36}$ Bevan JA, Bevan RD. Sympathetic control of the rabbit basilar artery. In: Proceedings of the International Symposium on Neurogenic Control of the Brain Circulation. Oxford: Pergamon Press, 1977.

${ }^{37}$ Heistad DD, Marcus ML, Gross PM. Effects of sympathetic nerves on cerebral vessels in dog, cat, and monkey. Am J Physiol 1978;235:H544-H552.

${ }^{38}$ Betz E. Cerebral blood flow: its measurement and regulation. Physiol Rev 1972;52:595-630.

${ }^{39}$ Reivich M. Regulation of the cerebral circulation. Clin Neurosurg 1969;16:378-418.

${ }^{40}$ Seylaz J, Sercombe R, Lacombe P, Pinard E, ReynierRebuffel AM, Aubineau P, Mamo H. Study of the 
effects of the sympathetic stimulation on cerebral blood flow by means of three complementary techniques. In: Proceedings of the International Symposium on Neurogenic Control of the Brain Circulation. Oxford: Pergamon Press, 1977.

${ }^{41}$ Deshmukh VD, Harper AM, Rowan JO, Jennett WB. Studies on neurogenic control of the cerebral circulation. In: Proceedings of the 5th International Symposium on $C B F$ regulation, acid-base and energy metabolism. Basel: Karger, 1972.

${ }^{42}$ Harper AM, Deshmukh VD, Rowan JO, Jennett WB. The influence of sympathetic nervous activity on cerebral blood flow. Arch Neurol 1972;27:1-6.

${ }^{43}$ James JM, Millar RA, Purves MJ. Observations on the extrinsic neural control of cerebral blood flow in the baboon. Circulat Res 1969;25:77-93.

${ }^{44}$ Harper AM, Deshmukh VD, Fitch W, Graham DI, MacKenzie ET. Effect of cervical sympathetic stimulation and ablation in normotensive, hypotensive and hypertensive primates. In: Proceedings of the International Symposium on Neurogenic Control of the Brain Circulation. Oxford: Pergamon Press, 1977.
${ }^{45}$ Kogure K, Scheinberg P, Kishikawa H, Utsunomiya Y, Busto R. Adrenergic control of cerebral blood flow and energy metabolism in the rat. Stroke 1979;10:179-84.

${ }^{46}$ Bill A, Linder M, Linder J. Interactions between adrenergic and autoregulatory mechanisms in the control of cerebral and retinal blood flow. In: Proceedings of the International Symposium on Neurogenic Control of the Brain Circulation. Oxford: Pergamon Press, 1977.

${ }^{47}$ Edvinsson L, Hardebo JE, Owman CH. Influence of the cerebro-vascular sympathetic innervation on regional flow, auto-regulation, and blood-brain-barrier function. In: Proceedings of the International Symposium on Neurogenic Control of the Brain Circulation. Oxford: Pergamon Press, 1977.

${ }^{48}$ Mueller M, Ertel PJ, Felten DL, Overhage JM. Sympathetic nerves protect against blood-brain-barrier disruption in the spontaneously hypertensive rat. Stroke 1982;13:83-8. 